\title{
BIMBINGAN TEKNIS KULTUR MIKROALGA BAGI TEKNISI BALAI BENIH PERIKANAN KENDARI SULAWESI TENGGARA
}

\author{
Wa Iba ${ }^{*}$, La Ode Baytul Abidin, dan Indrayani \\ Fakultas Perikanan dan IImu Kelautan, Universitas Halu Oleo, Kendari \\ Jl. HEA Mokodompit Kampus Hijau Bumi Tridharma Anduonohu Kendari Sulawesi Tenggara \\ ${ }^{*}$ Korespondensi: wa.iba@uho.ac.id
}

Diterima 17 November 2018 / Disetujui 25 Desember 2018

\begin{abstract}
ABSTRAK
Balai Benih Perikanan (BBP) Kendari merupakan Unit Pelaksana Teknis Daerah (UPTD) di bawah koordinasi Dinas Kelautan dan Perikanan Provinsi Sulawesi Tenggara (Sultra). Tugas pokok UPTD BBP Kendari adalah melakukan usaha pembenihan ikan dan udang untuk supply di daerah Sultra dan sekitarnya. Pembenihan ikan dan udang lebih banyak mengalami kegagalan sehingga BBP Kendari tidak mampu melalukan supply benih ke pembudidaya. Akibatnya pembudidaya di Sultra membeli benih dari luar provinsi sehingga meningkatkan biaya produksi mereka dan menurunkan produktivitas usaha budidaya. Salah satu faktor utama yang menjadi alasan kegagalan BBP Kendari dalam produksi benih ikan dan udang adalah belum tersedianya kultur mikroalga atau phytoplankton yang berkelanjutan dalam panti pembenihannya (hatchery). Hal ini disebabkan oleh kurang memadainya skill dan pengetahuan staf dan teknisi hatchery BBP Kendari terkait kultur mikroalga sebagai pakan larva ikan dan udang. Oleh karena itu tim dari Lembaga Penelitian dan Pengabdian Kepada Masyarakat Universitas Halu Oleo mengadakan bimbingan teknis (bimtek) kultur mikroalga kepada para teknisi dan staf BBP Kendari sehingga mereka mampu untuk a) menguasai teknik sterilisasi alat dan media kultur mikroalga, b) mengidentifikasi jenis-jenis mikroalga untuk pakan alami ikan dan udang serta c) melakukan starter dan scale-up kultur mikroalga. Kegiatan pengabdian masyarakat dalam Program Kemitran Masyarakat (PKM) ini dalam bentuk bimtek kultur mikroalga telah dilaksanakan selama 1 bulan yaitu dari bulan OktoberNovember 2018 sejak persiapan hingga seminar dan penyusunan laporan akhir. Peserta bimtek adalah sesuai target yaitu 12 orang staf dan teknisi BBP Kendari serta 3 mahasiswa BDP FPIK dan Bioteknologi FMIPA UHO, sehingga transfer teknologi dan skill telah berjalan secara optimal.
\end{abstract}

Kata Kunci: bimtek, pengabdian, mikroalga, Kendari

\section{PENDAHULUAN}

Mikroalga atau phytoplankton adalah salah satu jenis pakan alami yang keberadaannya dalam balai benih perikanan (hatchery) sangat penting (Hemaiswarya et al., 2011; lba et al.,
2014). Mikroalga juga dipakai secara terus menerus untuk pakan berbagai kerang budidaya seperti kerang hijau (green mussels) dan tiram (oysters) serta landak laut (Gonzalez-Araya, 2011; Carboni et al., 2012). Sebagai basis dalam rantai 
makanan perairan dan kandungan nutrisinya yang memadai, mikroalga merupakan pakan alami pertama yang harus diberikan kepada larva udang dan ikan dalam hatchery setelah fase kuning telur selesai (Conceiao et al., 2010; Carboni et al., 2012; Skjånes et al., 2011; Peres-Lopez et al., 2013; Halima, 2017; Shah et al., 2017). Mikroalga digunakan juga sebagai pakan bagi pakan alami yang lain seperti artemia dan rotifer yang menetukan kelangsungan hidup larva ikan dan udang dalam hatchery sampai siap untuk dijual dalam bentuk benih (Carboni et al., 2011; lba et al., 2014). Disamping itu penggunaan mikroalga dalam pemeliharaan larva ikan dan udang dengan sistim green water technique telah terbukti mampu meningkatkan kelangsungan hidup larva ikan dan udang (Conceiao et al., 2010; Carboni et al., 2011; Iba et al., 2014., Halima, 2017). Oleh karena itu ketersediaan kultur mikroalga yang siap untuk dipanen setiap saat sebagai pakan dalam hatchery sangat menentukan keberhasilan hatchery tersebut.

Walaupun mikroalga tersedia melimpah di berbagai microhabitat perairan tawar dan laut, tetapi hanya beberapa jenis yang telah dikultur secara luas untuk kepentingan pembenihan di hatchery. Hal ini disebabkan karena teknik kultur spesies-spesies tersebut yang telah dikuasai dan nilai nutrisi yang memenuhi syarat untuk larva ikan dan udang terutama dari golongan asam lemak rantai panjang, polyunsaturated fatty acids (PUFA) yang sangat dibutuhkan oleh pertumbuhan dan metamorphosis larva ikan dan udang. Beberapa jenis mikroalga yang telah banyak yang dikultur dan umum digunakan dalam hatchery antara lain dari jenis diatom seperti Chaetocores neogracile, C. muelleri, Thalassiosira pseudonana, T. weissflogii, Skeletonema costatum, alga hijau seperti Tetraselmis chuii dan Chorella minutissima, Chorella sp., Tisochrysis lutea dan cyanobacteria seperti Spirulina sp (Halima, 2017; Hemaiswarya et al., 2011; lba et al., 2014). Teknik kultur yang digunakan untuk berbagai spesies tersebut bervariasi bergantung kepada nilai nutrisi yang akan dimaksimalkan.

BBP Kendari adalah salah satu UPTD di bawah Dinas Kelautan dan Perikanan Propinsi Sulawesi Tenggara yang bertugas untuk melakukan pembenihan ikan dan udang. Namun demikian sampai saat ini, UPTD BBP Kendari belum berfungsi secara maksimal karena beberapa kendala teknis, salah satunya adalah ketersediaan kultur mikroalga dalam proses pemeliharaan ikan dan udang yang masih terbatas dan tidak tersedia secara kontiyu. Hal ini telah menyebabkan kematian massal larva udang dan ikan mengakibatkan kerugian yang cukup signifikan (Iba, 2014). Berdasarkan hasil komunikasi dengan beberapa staf dan teknisi di BBP Kendari, diketahui bahwa keterbatasan supply mikroalga dan skill dalam kultur atau budidaya mikroalga merupakan kendala utama yang dihadapi mereka untuk menghasilkan benih ikan dan udang yang berkualitas dan jumlah yang memadai untuk dijual kepada pembudidaya. Oleh karena itu bimbingan teknis kultur mikroalga dari Lembaga Penelitian dan Pengabdian Kepada Masyarakat Universitas Halu Oleo (LPPM UHO) sangat penting dan mendesak untuk dilakukan guna membantu UPTD BBP Kendari melalui Program Kemitraan Masyarakat (PKM). 
Tujuan kegiatan ini adalah untuk membantu teknisi di Balai Benih Perikanan Kendari dan mahasiswa UHO yang tertarik dalam membudidayakan mikroalga untuk keperluan pembenihan udang dan ikan. Kegunaan kegiatan ini adalah sebagai bahan informasi tambahan dan acuan bagi BBP Kendari tentang metode budidaya mikroalga yang efektif dan efisien sebagai pakan alami bagi larva ikan dan udang sekaligus sebagai salah satu tambahan kepustakaan tentang metode budidaya mikroalga.

\section{METODE KEGIATAN}

Lokasi kegiatan pengabdian ini adalah di BBP Perikanan Kelurahan Purirano Kota Kendari yang berjarak sekitar $20 \mathrm{~km}$ dari Universitas Halu Oleo (Gambar 1). Masyarakat sasaran kegiatan ini adalah teknisi dan staf BBP Kendari yang berperan penting dalam produksi larva ikan dan udang untuk supply di daerah Sulawesi Tenggara serta mahasiswa UHO yang berminat terhadap pembudidayaan mikroalga

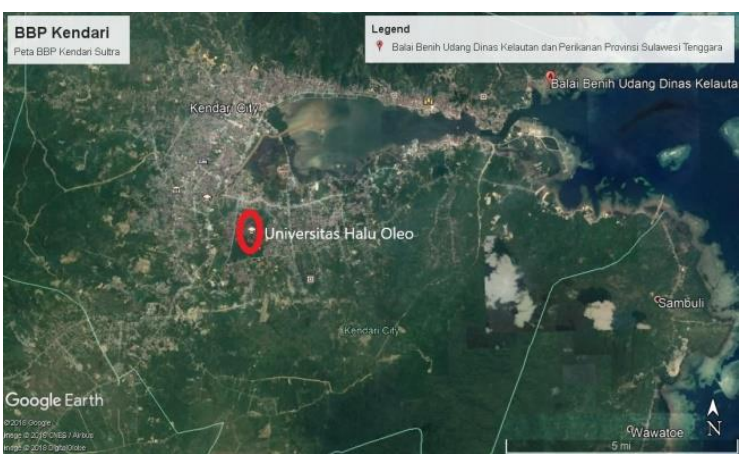

Gambar 1. Lokasi Program Kemitraan Masyarakat LPPM UHO.

Metode yang digunakan dalam kegiatan yaitu: sosialisasi kegiatan dengan mengundang teknisi dan staf BBP Kendari untuk memberikan gambaran tentang
Bimtek yang akan dilakukan. Setelah itu diadakan Bimtek Kultur Mikroalga untuk Hatchery di BBP Kendari. Bimtek ini diikuti oleh 12 orang staf dan teknisi BBP Kendari serat 6 orang mahasiswa FPIK dan 1 orang mahasiswa Bioteknologi FMIPA UHO untuk lebih memfokuskan alih teknologi dan peningkatan skill mereka. Materi yang diberikan dalam bimtek meliputi teknik sterilisasi alat dan media kultur, pengenalan jenis-jenis mikroalga yang digunakan sebagai pakan dalam hatchery, teknik kultur mikroalga dan teknik scale up mikroalga (Tabel 1 ). Jenis mikroalga yang dipakai dalam Bimtek ini adalah $T$. chui dan Chlorella sp. yang merupakan spesies mikroalga yang banyak digunakan dalam hatchery ikan dan udang (Gambar 2).

Teknologi yang telah ditransfer dalam program pengabdian masyarakat ini adalah teknik kultur mikroalga menggunakan media $\mathrm{f} / 2$ pada salinitas air laut (28-30 ppt). Kultur mikroalga dimulai dari sterilisasi alat dan media kultur. Sterilisasi dilakukan dengan menggunakan autoclave untuk semua alat dan bahan yang digunakan dalam kultur mikroalga untuk mencegah kontaminasi dari bakteri. Sterilisasi dilakukan untuk fase starter kultur mikroalga. Dalam fase ini digunakan labu erlenmeyer dengan volume $100 \mathrm{~mL}$. Sedangkan untuk fase scale-up, air laut yang akan dicampurkan dalam media $1 / 2$ disaring menggunakan metode konvesional saringan air sederhana. Fase scale up untuk keperluan pembenihan larva ikan dan udang tidak perlu menggunakan mikroalga yang bebas bakteri (axenic). Pada fase ini, kultur mikroalga menggunakan toples plastik biasa dengan volume 5 liter (Gambar 2). 


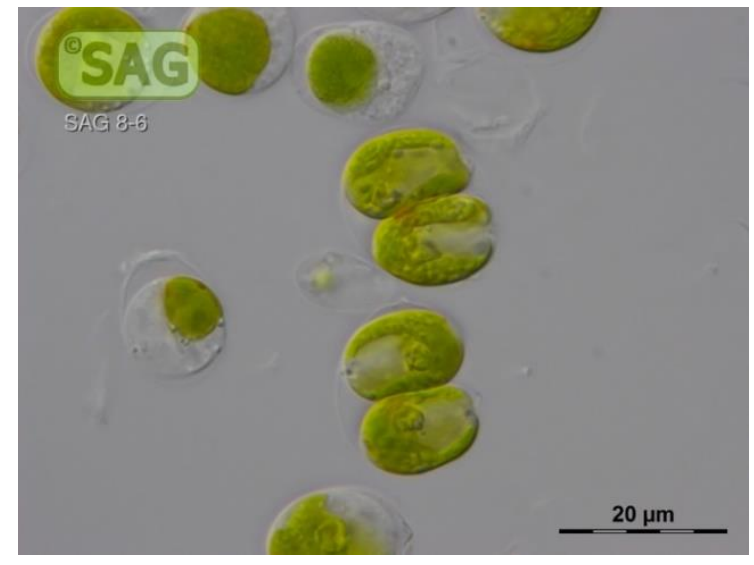

A

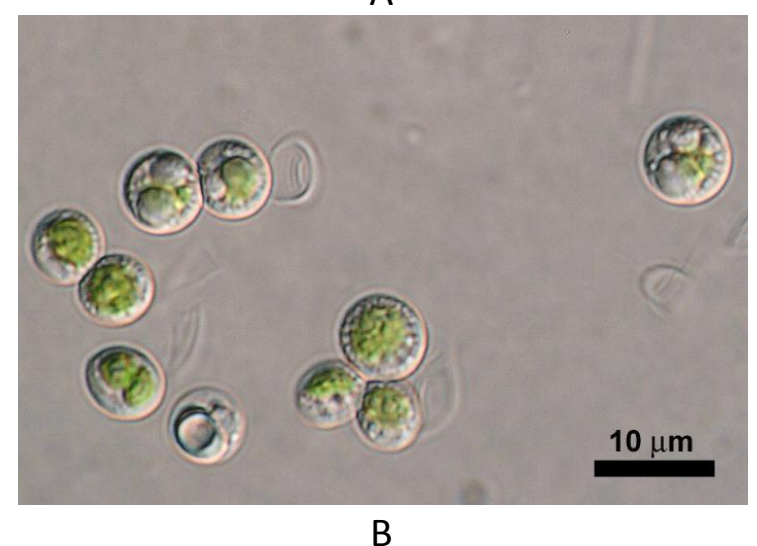

Gambar 2. Spesies mikroalga yang digunakan dalam bimtek kultur mikroalga, $\mathrm{A}=T$. chui. $\mathrm{B}=$ Chlorella sp.

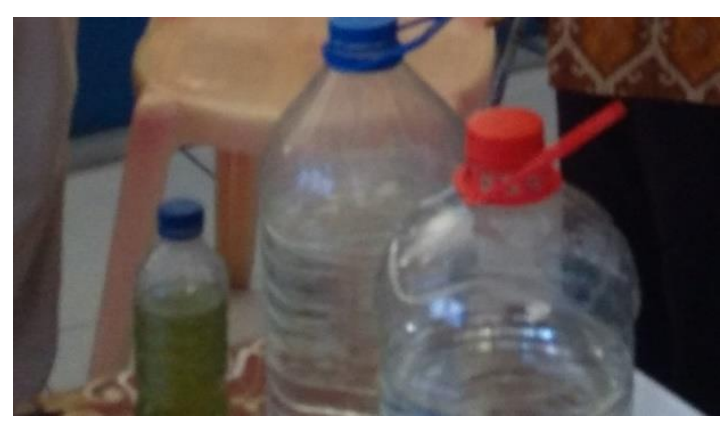

Gambar 3. Scale-up kultur mikroalga dengan volume $5 \mathrm{~L}$

Fase scale-up dilaksanakan di BBP Kendari dan saat telah dipelihara selama kurang lebih satu bulan (Gambar 4). Metode kultur adalah batch dengan memanen seluruh biomassa mikroalga sekaligus. Stok kultur diambil dari hasil kultur scale-up dan disimpan di laboratorium hatchery untuk penggunaan selanjutnya.

Bagian ini memberikan gambaran tentang waktu dan lokasi kegiatan, metode kegiatan pengabdian yang digunakan, dan prosedur kegiatan (step by step). Prosedur kegiatan perlu diuraikan dengan ringkas tapi cukup detail agar pembaca lain dapat mengerti apa yang dikerjakan.

\section{HASIL DAN PEMBAHASAN}

Kegiatan Bimtek ini dilaksanakan selama dua hari tanggal 31 Oktober-1 November 2018 dan diikuti oleh 12 orang peserta dari BBP Kendari yang terdiri dari teknisi BBP di Kel. Purirano dan BBP di Punggaluku, Konawe Selatan. Hari pertama kegiatan dilaksanakan di Laboratorium Pengujian FPIK UHO sedangkan hari kedua dilaksanakan di BBP Kel. Purirano Kota Kendari. Transfer ilmu dan teknologi yng dilakukan dalam bimtek ini telah tercapai berdasarkan hasil evaluasi setelah bimtek dilaksanakan. Semua perserta merasa bahwa bimtek ini sangat bermanfaat dan membantu dalam pelaksanaan tugas mereka sebagai teknisi di hatchery yang berhubungan dengan budidaya mikroalga untuk pakan alami larva ikan dan udang.

Capaian yang ditargetkan dalam bimtek untuk meningkatkan keterampilan peserta seperti mampu melakukan sterilisasi alat dan media kultur mikroalga, mampu mengidentifikasi secara morfologi beberapa spesies mikroalga yang umum dipakai dalam pembenihan ikan dan udang, mampu melakukan starter kultur mikroalga serta mampu melakukan scaleup kultur mikroalga telah tercapai selama kegiatan. Peserta cenderung percaya 
bahwa mereka akan bisa melakukan kultur sendiri namun akan tetap berkoordinasi dengan tim PKM jika sewaktu-waktu memerlukan bantuan.

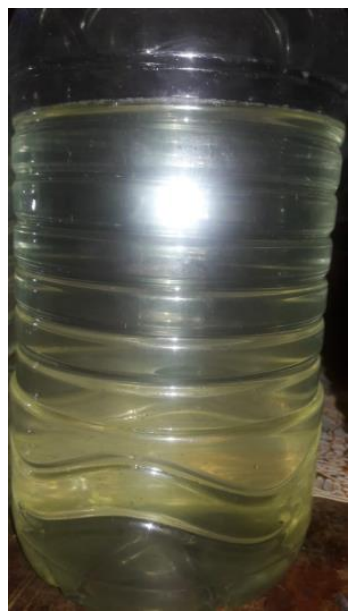

A

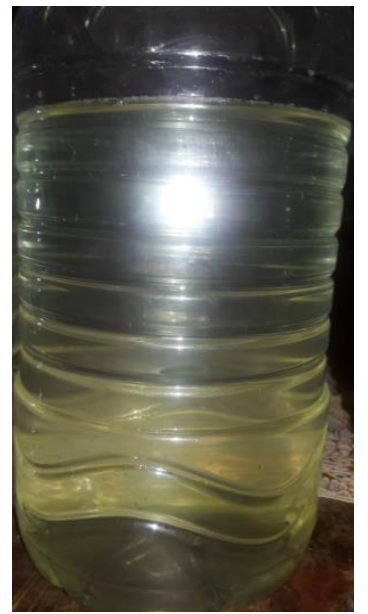

B
Gambar 4. Kondisi kultur T. chui (A) dan Chlorella sp. (B) hasil bimtek di BBP Kendari

Pada akhir kegiatan bimtek, peserta telah melakukan scale-up kultur mikroalga dari jenis Chlorella sp. dan $T$. chui. Saat ini kultur tersebut telah tersimpan di BBP Kel. Purirano Kota Kendari dan akan terus diremajakan untuk keperluan budidaya udang (Gambar 4).

\section{KESIMPULAN DAN SARAN}

\section{Kesimpulan}

Setelah pelaksanaan kegiatan, beberapa hal yang bisa disimpulkan dalam kegiatan pengabdian Program Kemitraan Masyarakat ini adalah telah erjadi peningkatan pengetahuan dan keterampilan dari teknisi dan staf BBP Kendari setelah mengikuti kegiatan bimtek dalam hal kultur mikroalga sejak sterilisasi hingga scale-up kultur. Selanjutnya stok mikroalga jenis $T$. chui dan Chlorella sp. berhasil dikultur dan disimpan di BBP Kendari.

\section{Saran}

Perlu pendampingan yang lebih teratur/regular bagi para teknisi BBP Kendari dalam hal kultur mikroalga untuk memastikan keberlanjutan stok yang telah disimpan di BBP Kendari Kel. Purirano Kota Kendari.

\section{UCAPAN TERIMA KASIH}

Terima kasih kami ucapkan kepada Universitas Halu Oleo yang telah membiayai kegiatan pengabdian ini melalui DIPA BLU UHO Nomor: 3887/UN.29.1/KU/2018. Terimakasih kami sampaikan pula kepada Kepala BBP Kendari Ir. Nasbir, M.M atas dukungannya sehingga kegiatan pengabdian ini bisa dilaksanakan dengan baik. Tak lupa pula kepada semua mahasiswa Universitas Halu Oleo yang tergabung dalam Microalgae Research Group terutama Ismi Musdalifah Darsan, Yusran, Saniati Goa, Nova and Yulina, kami ucapkan terima kasih atas bantuannya dalam mempersiapkan logistik kegiatan pengabdian ini.

\section{DAFTAR PUSTAKA}

Carboni, S., J. Vignier, M. Chiantore, D.R. Tocher and H. Migaud. 2012. Effects of dietary microalgae on growth, survival and fatty acid composition of sea urchin Paracentrotus lividus throughout larval development. Aquaculture. 324-325:250-258.

Conceicao, L.E.C., M. Yufera, P. Makridis, S. Morais and M.T. Dinis. 2010. Live feeds for early stages of fish rearing. Aquaculture Research.41:613-640.

Gonzalez-Araya, R., I. Que'au, C. Quere, J. Moal and R. Robert. 2011. A 
physiological and biochemical approach to selecting the ideal diet for Ostrea edulis (L.) broodstock conditioning (part A). Aquaculture Research. 42:710-726.

Halima, N.B. 2017. Why is it important to use algae in aquaculture? J Biochem Biotech 1:11-13.

Hemaiswarya, S., R. Raja, R. R. Kumar, V. Ganesan and C. Anbazhagan. 2011. Microalgae: a sustainable feed source for aquaculture. World Journal of Microbiology and Biotechnology 27:1737-1746.

Iba, W. 2016. The Potential of Indonesian Microalgal Strains to Support Eastern White Shrimp (Litopenaeus Vannamei) Aquaculture. Dissertasi. University of Rhode Island. 176p

Iba W., Rice M.A. \& Wikfors G.H. 2014. Microalgae in eastern pacific white shrimp, Litopenaeus vannamei (Boone 1931) hatcheries: a review on roles and culture environments. Asian Fisheries Science Journal. 27:12-233

Perez-Lopez, P., Gonzalez-Garcia, S., Jeffryes, S., Agathos, S.N., Mchugh, E., Walsh, D.J., Murray, P.M., Moane, S., Feijoo, G., Moreira, M.T. 2014. Life cycle assessment of the production of the red antioxidant carotenoid astaxanthin by microalgae: from lab to pilot scale. J Clean Prod. 64:332-44.

Skjånes, K., Céline Rebours, and Peter Lindblad. 2013. Potential for green microalgae to produce hydrogen, pharmaceuticals and other high value products in a combined process. Crit Rev Biotechnol. 33:172-215.

Shah, M.R., Giovanni Antonio Lutzu, G.A., Alam, A., Sarker, P., Chowdhury,
M.A.K., Parsaeimehr, A., Liang, Y., Daroch, M. 2017. Microalgae in aquafeeds for a sustainable aquaculture industry. J Appl Phycol. DOI 10.1007/s10811-017-1234-z. 